\title{
Oral misoprostol for induction of labour at term: randomised controlled trial
}

Jodie M Dodd, Caroline A Crowther, Jeffrey S Robinson

\begin{abstract}
Objective To compare oral misoprostol solution with vaginal prostaglandin gel (dinoprostone) for induction of labour at term to determine whether misoprostol is superior.

Design Randomised double blind placebo controlled trial. Setting Maternity departments in three hospitals in Australia. Population Pregnant women with a singleton cephalic presentation at $\geq 36+6$ weeks' gestation, with an indication for prostaglandin induction of labour.

Interventions $20 \mu \mathrm{g}$ oral misoprostol solution at two hourly intervals and placebo vaginal gel or vaginal dinoprostone gel at six hourly intervals and placebo oral solution.

Main outcome measures Vaginal birth within 24 hours; uterine hyperstimulation with associated changes in fetal heart rate; caesarean section (all); and caesarean section for fetal distress. Results 741 women were randomised, 365 to the misoprostol group and 376 to the vaginal dinoprostone group. There were no significant differences between the two treatment groups in the primary outcomes: vaginal birth not achieved in 24 hours (misoprostol 168/365 (46.0\%) $v$ dinoprostone 155/376 $(41.2 \%)$; relative risk $1.12,95 \%$ confidence interval 0.95 to 1.32 ; $\mathrm{P}=0.134)$, caesarean section $(83 / 365(22.7 \%) v 100 / 376$ $(26.6 \%) ; 0.82,0.64$ to $1.06 ; \mathrm{P}=0.127)$, caesarean section for fetal distress (32/365 (8.8\%) v 35/376 (9.3\%); 0.91, 0.57 to 1.44; $\mathrm{P}=0.679)$, or uterine hyperstimulation with changes in fetal heart rate $(3 / 365(0.8 \%) v 6 / 376(1.6 \%) ; 0.55,0.14$ to 2.21 ; $\mathrm{P}=0.401)$. Although there were differences in the process of labour induction, there were no significant differences in adverse maternal or neonatal outcomes.

Conclusions This trial shows no evidence that oral misoprostol is superior to vaginal dinoprostone for induction of labour. However, it does not lead to poorer health outcomes for women or their infants, and oral treatment is preferred by women.

Trial registration National Health and Medical Research Council, Perinatal Trials, PT0361.
\end{abstract}

\section{Introduction}

Induction of labour is a common intervention, ${ }^{1}$ performed for medical, obstetric, or social indications. In 2002 in Australia, nearly $27 \%$ of pregnant women had their labour induced. ${ }^{2}$ Prostaglandins to induce labour are used in about $23 \%$ of all confinements. ${ }^{3}$ Misoprostol is an oral prostaglandin compound, structurally related to prostaglandin $\mathrm{E}_{1}{ }^{4}$ and manufactured as a treatment for peptic ulcer disease. ${ }^{56}$ Though unlicensed for this indication, misoprostol is being used increasingly in induction of labour, with vaginal ${ }^{7}$ and oral $^{8}$ administration.
We conducted a randomised double blind trial to compare $20 \mu \mathrm{g}$ oral misoprostol solution with vaginal prostaglandin gel (dinoprostone) for induction of labour at term.

\section{Methods}

The study took place at the Women's and Children's Hospital and Lyell McEwin Health Service (South Australia) and the Hervey Bay Hospital (Queensland) between April 2001 and December 2004.

\section{Inclusion and exclusion criteria}

If the attending obstetrician decided to induce labour we approached any women with a singleton pregnancy at $\geq 36+6$ weeks' gestation. We then obtained written informed consent. We excluded women with a "favourable" cervix (defined as a modified Bishop score of $\geq 7$ ), any contraindication to vaginal birth, previous uterine surgery (including caesarean section), or ruptured membranes.

\section{Randomisation schedule and allocation}

The randomisation schedule was generated by using a computer sequence with variable blocks and stratification for parity $(0$ and 1-4) and collaborating centre. The point of randomisation was when the pack was opened. Treatment packs appeared identical and were sealed to prevent tampering.

On admission to the delivery suite the midwife confirmed the trial entry details and allocated a study number by taking the next sequentially numbered, identically appearing treatment pack appropriate for the woman's parity. We also reconfirmed consent at this time.

\section{Treatment schedules}

Misoprostol-Each misoprostol pack contained six labelled bottles with $100 \mu \mathrm{g}$ of crushed misoprostol and two doses of vaginal placebo (tylose) gel in sterile opaque syringes.

Dinoprostone -Each placebo pack contained six labelled white plastic bottles with $25 \mathrm{mg}$ of crushed vitamin B-6 and two doses of dinoprostone gel in sterile opaque syringes and sealed in sterile opaque packages ( $2 \mathrm{mg}$ for nulliparous women and $1 \mathrm{mg}$ for multiparous women).

If the tracing on the fetal cardiotocogram was within normal limits the the study preparation was given. The midwife or attending doctor performed a vaginal examination, recorded the initial Bishop score, and administered the gel.

The midwife made up the oral solution immediately before administration by mixing the powder with $100 \mathrm{ml}$ of water to produce a solution of $1 \mu \mathrm{g} / \mathrm{ml}$ of misoprostol in the active solution. The woman then took a $20 \mathrm{ml}$ aliquot of solution $(20 \mu \mathrm{g}$ misoprostol solution). This procedure was repeated every two 
Table 1 Cost to the hospital associated with induction of labour

\begin{tabular}{lc} 
Item & Cost $(\mathbf{\$ A})^{*}$ \\
\hline $1: 2$ midwifery care & $13.04 /$ hour \\
\hline $1: 1.25$ midwifery care & $32.60 /$ hour \\
\hline Misoprostol & $0.35 / 200 \mu \mathrm{g}$ \\
\hline Vaginal dinoprostone gel & $40.17 / 1 \mathrm{mg} ; 51.64 / 2 \mathrm{mg}$ \\
\hline Vaginal birth & 3973.83 \\
\hline Caesarean birth $^{*}$ & 6349.97 \\
\hline
\end{tabular}

$\$ A 1=\{0.43, € 0.62$

*Including average length of hospital stay.

hours (to a maximum of six doses in 12 hours). The vaginal gel was administered every six hours (to a maximum of two doses in 12 hours). All care was according to local hospital guidelines, except for the administration of trial medications as described.

Six weeks after the birth we posted women a questionnaire relating to satisfaction with care. If they did not return the questionnaire within two weeks we contacted them by telephone and they completed the questionnaire over the phone.

\section{Outcome measures}

Our primary outcome measures were vaginal birth not achieved in 24 hours (including women who achieved vaginal birth after 24 hours and those women who had a caesarean section), caesarean section (all and for heart rate tracing indicating fetal distress), and uterine hyperstimulation with changes in fetal heart rate.

We defined uterine hyperstimulation as uterine tachysystole (with five or more contractions in a 10 minute period for two consecutive 10 minute periods) or uterine hypertonus (a uterine contraction lasting for more than two minutes)..$^{10}$ The changes in fetal heart rate that we considered abnormal included persistent decelerations (early, late, or variable decelerations), fetal tachycardia (fetal heart rate $>160$ beats per minute), fetal bradycardia (fetal heart rate $<100$ beats per minute), or reduced short term variability $\left(<5\right.$ beats per minute). ${ }^{11}{ }^{12} \mathrm{~A}$ single investigator blinded to the treatment allocated reviewed all fetal heart rate tracings from an induced labour to maintain consistency in interpretation.

We measured labour and birth complications, neonatal complications, maternal complications and side effects, and maternal satisfaction with care as secondary outcomes. ${ }^{9}$ We compared costs with clinical pathways built into the model from the perspective of the healthcare institution (table 1). The midwifery care during induction was costed at a rate of one midwife caring for two women, and care during labour and birth was costed at a rate of 1.25 midwives caring for a single woman, according to hospital standards.

The midwife caring for the woman completed data forms, which were confirmed and checked before hospital discharge. Data were entered into a database created in Microsoft Access 97.

\section{Data analysis}

We analysed data on an intention to treat basis, blind to the allocated treatment, using SAS, version 9 (SAS Institute, Cary, NC). Dichotomous outcomes were compared with $\chi^{2}$ tests or Fisher's exact test, with calculation of relative risks and $95 \%$ confidence intervals. We used Student's $t$ test to compare normally distributed continuous data and non-parametric tests (Wilcoxon rank sum) for skewed data. The number of women needed to treat to benefit (NNTB) and to harm (NNTH) with 95\% confidence intervals was calculated for significant outcomes. Before the analysis of any outcomes, we considered baseline characteristics and corrected those sufficiently imbalanced

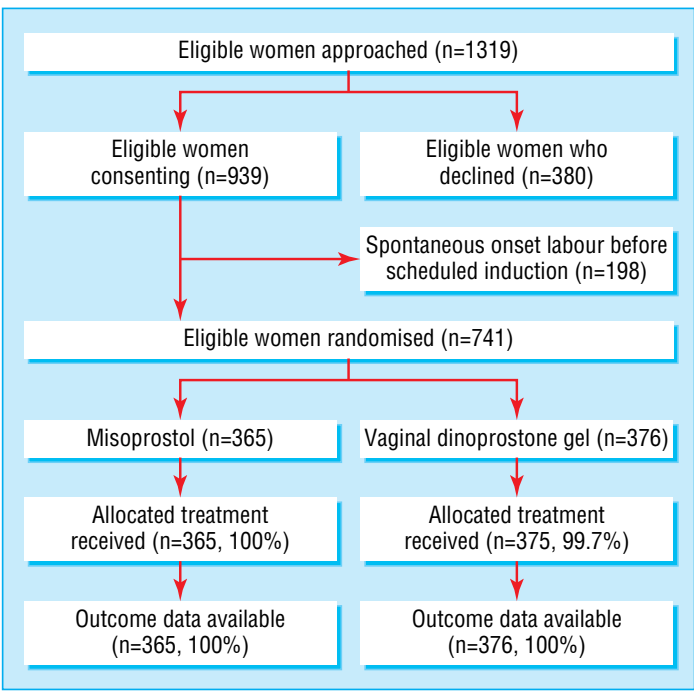

Flow of women through trial

(more than 5\% difference between treatment groups) using log binomial regression techniques. $\mathrm{P}<0.05$ was considered significant.

\section{Sample size}

Using information from the Cochrane review, ${ }^{8}$ we calculated that a sample size of 738 women would give $85 \%$ power to detect a $50 \%$ difference in the number of women who did not achieve a vaginal birth after 24 hours from $20 \%$ in the vaginal dinoprostone group to $30 \%$ in the misoprostol group $(\mathrm{P}<0.05)$, a $32 \%$ difference in caesarean section from $28 \%$ in the vaginal dinoprostone group to $19 \%$ in the misoprostol group, and a threefold difference in the rate of hyperstimulation with changes in fetal heart rate from $2 \%$ in the vaginal dinoprostone group to $6 \%$ in the misoprostol group $(\mathrm{P}<0.05$; power $80 \%)$.

\section{Results}

\section{Baseline characteristics at trial entry}

Of 1319 eligible women approached, $939(71.2 \%)$ provided written consent (figure). Of these, 741 (78.8\%) were admitted for induction of labour and randomised, 365 women to oral misoprostol, and 376 to vaginal dinoprostone. In total, 740 (99.9\%) women received treatment as allocated. We had outcome data for all 741 women up to hospital discharge (figure).

Baseline characteristics were comparable except for initial Bishop score (table 2). We adjusted for this in the analyses and have presented adjusted results.

\section{Primary outcomes}

There were no significant differences between the two treatment groups for vaginal birth not achieved in 24 hours (misoprostol $46.0 \% v$ dinoprostone $41.2 \%$ ), caesarean section (22.7 $\% v 26.6 \%$ ), caesarean section for fetal distress $(8.8 \% v 9.3 \%)$, or uterine hyperstimulation with changes in fetal heart rate $(0.8 \% v 1.6 \%)$ (table 3).

\section{Secondary outcomes}

Women in the oral misoprostol group were more likely to have a low Bishop score $(<7) 24$ hours after the induction was started, to require vaginal dinoprostone gel, to have infusion of oxytocin, and to have a longer time between induction and birth (table 4). For every 15 women treated with misoprostol, one required further dinoprostone gel (NNTH 15, 95\% confidence interval 12 to 
Research

Table 2 Baseline variables at trial entry. Figures are numbers (percentages) of women unless stated otherwise

\begin{tabular}{|c|c|c|}
\hline & $\begin{array}{c}\text { Misoprostol } \\
(\mathrm{n}=365)\end{array}$ & $\begin{array}{c}\text { Dinoprostone } \\
(n=376)\end{array}$ \\
\hline Mean (SD) age (years) ${ }^{\star}$ & $27.9(5.6)$ & $28.0(5.6)$ \\
\hline Nulliparous & $213(58.4)$ & $221(58.8)$ \\
\hline White & $355(97.3)$ & $362(96.3)$ \\
\hline Public patient & $362(99.2)$ & $376(100.0)$ \\
\hline \multicolumn{3}{|l|}{ Indication for induction of labour: } \\
\hline After due date & $181(49.6)$ & $175(46.5)$ \\
\hline Pre-eclampsia & $30(8.2)$ & $37(9.8)$ \\
\hline Hypertension & $49(13.4)$ & $55(14.6)$ \\
\hline Intrauterine growth restriction & $24(6.6)$ & $32(8.5)$ \\
\hline Abnormal glucose tolerance & $29(8.0)$ & $46(12.2)$ \\
\hline Social & $55(15.1)$ & $46(12.2)$ \\
\hline Other & $21(5.8)$ & $25(6.6)$ \\
\hline \multicolumn{3}{|l|}{ Initial Bishop score: } \\
\hline $0-3$ & $246(67.4)$ & $214(56.9)$ \\
\hline $4-6$ & $119(32.6)$ & $162(43.1)$ \\
\hline Mean (SD) gestational age (weeks) ${ }^{\star}$ & $40.6(2.0)$ & $40.4(2.1)$ \\
\hline Mean (SD) height $(\mathrm{m})^{*}$ & $165.1(5.8)$ & $165.0(6.6)$ \\
\hline Median (IQR) weight at booking (kg) & $72.0(48.0-96.0)$ & $75.0(49.0-101.0)$ \\
\hline BMI $>30\left(\mathrm{~kg} / \mathrm{m}^{2}\right)$ at booking & $94(34.0)$ & $98(33.1)$ \\
\hline Smoking at booking & $84(23.0)$ & $86(22.9)$ \\
\hline
\end{tabular}

IQR=interquartile range; $B M I=$ body mass index.

4021), and for every 13 women treated with misoprostol, one required infusion of oxytocin (13, 7 to 162$)$.

For every 30 women treated with oral misoprostol, there will be one less with uterine hyperstimulation without changes in fetal heart rate (NNTB 30; 18 to 95). The use of analgesia was high in both groups, and there were no significant differences between the two groups for other labour and birth complications (table 4). There were no significant differences in the occurrence of neonatal complications, maternal complications, or side effects (table 4).

Over half of the women $(58.5 \%)$ expressed a preference for an oral induction agent, and those women in the misoprostol group were more likely to say that they "liked everything" with their labour and birth.

The cost per woman induced with misoprostol was \$A4948.81 compared with $\$$ A5059.64 for vaginal dinoprostone gel, a difference of $\$ A 110.83$ ( $€ 69.13, £ 47.25)$ in favour of misoprostol (range $\$ A 15.88$ to $\$$ A121.87) (table 5).

\section{Discussion}

Oral misoprostol was not associated with significant differences in the number of women who achieve vaginal birth within 24 hours after induction, caesarean section, or uterine hyperstimu-

Table 3 Primary outcomes. Figures are numbers (percentages)

\begin{tabular}{lcccc} 
Outcome & $\begin{array}{c}\text { Misoprostol } \\
\mathbf{( n = 3 6 5 )}\end{array}$ & $\begin{array}{c}\text { Dinoprostone } \\
\mathbf{( n = 3 7 6 )}\end{array}$ & $\begin{array}{c}\text { Relative risk } \\
\mathbf{( 9 5 \% ~ C l )}\end{array}$ & $\begin{array}{c}\mathbf{P} \\
\text { value }\end{array}$ \\
\hline $\begin{array}{l}\text { Vaginal birth not achieved in 24 } \\
\text { hours }\end{array}$ & $168(46.0)$ & $155(41.2)$ & $\begin{array}{c}1.12 \\
(0.95 \text { to 1.32) }\end{array}$ & 0.134 \\
\hline Uterine HSS with changes in FHR & $3(0.8)$ & $6(1.6)$ & $\begin{array}{c}0.55 \\
(0.14 \text { to 2.21) }\end{array}$ & 0.401 \\
\hline Caesarean section: & & & & 0.82 \\
\hline All & $83(22.7)$ & $100(26.6)$ & $\begin{array}{c}0.82 \\
(0.64 \text { to } 1.06)\end{array}$ & 0.127 \\
\hline For fetal distress & $32(8.8)$ & $35(9.3)$ & $\begin{array}{c}0.91 \\
(0.57 \text { to 1.44) }\end{array}$ & 0.679 \\
\hline
\end{tabular}

HSS=hyperstimulation syndrome; FHR=fetal heart rate.

${ }^{*}$ Adjusted for initial Bishop score at trial entry.
Table 4 Secondary outcomes. Figures are numbers (percentages) unless stated otherwise

\begin{tabular}{|c|c|c|c|c|}
\hline Outcome & $\begin{array}{l}\text { Misoprostol } \\
\quad(n=365)\end{array}$ & $\begin{array}{c}\text { Dinoprostone } \\
(\mathrm{n}=376)\end{array}$ & $\begin{array}{l}\text { Relative risk } \\
(95 \% \mathrm{Cl})^{*}\end{array}$ & P value† \\
\hline \multicolumn{5}{|l|}{ Evidence of effect } \\
\hline $\begin{array}{l}\text { Bishop score }<7 \text { after } 24 \\
\text { hours }\end{array}$ & $57(15.6)$ & $39(10.4)$ & $\begin{array}{c}1.51 \\
(1.03 \text { to } 2.20)\end{array}$ & 0.031 \\
\hline $\begin{array}{c}\text { Further doses of } \\
\text { dinoprostone }\end{array}$ & 70 (19.2) & 47 (12.5) & $\begin{array}{c}1.41 \\
(1.01 \text { to } 1.97)\end{array}$ & 0.043 \\
\hline 0xytocin infusion & $203(55.6)$ & 179 (47.6) & $\begin{array}{c}1.17 \\
(1.01 \text { to } 1.34)\end{array}$ & 0.034 \\
\hline $\begin{array}{l}\text { Median (IQR) } \\
\text { induction-birth interval } \\
\text { (hours) }\end{array}$ & $\begin{array}{c}21.2 \\
(8.6-33.8)\end{array}$ & $\begin{array}{c}18.4 \\
(6.3-30.5)\end{array}$ & - & $<0.001 \ddagger$ \\
\hline
\end{tabular}

Labour and birth complications

\begin{tabular}{lllll}
\hline Uterine HSS-no changes in & $4(1.1)$ & $17(4.5)$ & 0.23 & 0.009
\end{tabular}

FHR

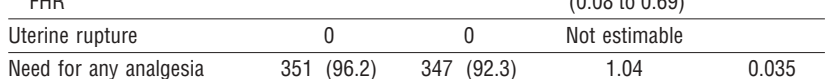

\begin{tabular}{lllcc}
\hline Need for any analgesia & $351(96.2)$ & $347(92.3)$ & 1.04 & 0.035 \\
\hline
\end{tabular}

\begin{tabular}{lcccc}
\hline Need for epidural & $243(66.6)$ & $229(60.9)$ & 1.08 & 0.149 \\
\end{tabular}

\begin{tabular}{lcccc}
\hline Meconium stained liquor & $59(16.2)$ & $52(13.8)$ & $\begin{array}{c}1.14 \\
\text { (0.81 to 1.61) }\end{array}$ & 0.465 \\
\hline
\end{tabular}

\begin{tabular}{llll}
\hline Mean (SD) length of labour & $7.5(4.1)$ & $6.9(4.0)$ & $0.073 \S$
\end{tabular}

(hours)

\begin{tabular}{|c|c|c|c|c|}
\hline Instrumental vaginal birth & $65(17.8)$ & $63(16.8)$ & $\begin{array}{c}1.06 \\
\text { (0.77 to } 1.46)\end{array}$ & 0.712 \\
\hline Blood loss $>600 \mathrm{ml}$ & $57(15.6)$ & 77 (20.5) & $\begin{array}{c}0.76 \\
(0.55 \text { to } 1.04)\end{array}$ & 0.081 \\
\hline Blood loss $>1000 \mathrm{ml}$ & $17(4.7)$ & $20(5.3)$ & $\begin{array}{c}0.86 \\
\text { (0.46 to } 1.63)\end{array}$ & 0.646 \\
\hline Need for blood transfusion & $8(2.2)$ & $9(2.4)$ & $\begin{array}{c}0.96 \\
\text { (0.37 to 2.47) }\end{array}$ & 0.927 \\
\hline \multicolumn{5}{|l|}{ Neonatal complications } \\
\hline Birth weight $<2500 \mathrm{~g}$ & $15(4.1)$ & $11(2.9)$ & $\begin{array}{c}1.30 \\
\text { (0.60 to } 2.79)\end{array}$ & 0.505 \\
\hline Apgar $<7$ at 5 minutes & $2(0.6)$ & $5(1.3)$ & $\begin{array}{c}0.42 \\
\text { (0.08 to } 2.15 \text { ) }\end{array}$ & 0.297 \\
\hline Cord $\mathrm{pH}<7.18$ & $10(7.6)$ & $19(11.6)$ & $\begin{array}{c}0.62 \\
(0.30 \text { to } 1.29)\end{array}$ & 0.205 \\
\hline NICU admission & $5(1.4)$ & $2(0.5)$ & $\begin{array}{c}2.66 \\
(0.52 \text { to } 13.75)\end{array}$ & 0.242 \\
\hline Neonatal encephalopathy & 0 & 0 & Not estimable & \\
\hline Neonatal deathף & 0 & 0 & Not estimable & \\
\hline \multicolumn{5}{|l|}{ Maternal complications } \\
\hline Any side effect & $76(20.8)$ & $99(26.3)$ & $\begin{array}{c}0.78 \\
\text { (0.60 to } 1.01)\end{array}$ & 0.063 \\
\hline Nausea & $20(5.5)$ & $30(8.0)$ & $\begin{array}{c}0.68 \\
\text { (0.39 to } 1.19)\end{array}$ & 0.175 \\
\hline Vomiting & $4(1.1)$ & $10(2.7)$ & $\begin{array}{c}0.43 \\
\text { (0.14 to } 1.37 \text { ) }\end{array}$ & 0.154 \\
\hline Diarrhoea & $5(1.4)$ & $9(2.4)$ & $\begin{array}{c}0.53 \\
\text { (0.18 to } 1.57)\end{array}$ & 0.250 \\
\hline Flushing & $6(1.6)$ & $4(1.1)$ & $\begin{array}{c}1.43 \\
\text { (0.41 to } 5.05) \\
\end{array}$ & 0.578 \\
\hline $\begin{array}{l}\text { Intensive care unit } \\
\text { admission }\end{array}$ & 0 & 0 & Not estimable & \\
\hline Hyperpyrexia & 0 & 0 & Not estimable & \\
\hline Coma & 0 & 0 & Not estimable & \\
\hline Maternal death & 0 & 0 & Not estimable & \\
\hline
\end{tabular}

IQR=interquartile range; $H S S=$ hyperstimulation syndrome; FHR=fetal heart rate; NICU=neonatal intensive care unit.

${ }^{*}$ Adjusted for initial Bishop score at trial entry.

$\dagger \chi^{2}$ unless otherwise specified.

$\ddagger$ Wilcoxon rank sum test.

$\S$ Student's $t$ test.

IDeath of liveborn infant within 28 days of birth.

lation with changes in fetal heart rate, compared with vaginal dinoprostone gel.

Oral misoprostol was associated with an increased need for further doses of vaginal dinoprostone gel and infusion of oxytocin, but a significant reduction in uterine hyperstimulation 
Table 5 Costs $(\$ A)$ for all women

\begin{tabular}{|c|c|c|c|c|}
\hline \multirow{2}{*}{ Outcome measured } & \multicolumn{2}{|c|}{ Misoprostol group ( $\mathrm{n}=365)$} & \multicolumn{2}{|c|}{ Dinoprostone $(\mathrm{n}=376)$} \\
\hline & No of units & Cost & No of units & Cost \\
\hline $\begin{array}{l}\text { Median length of labour (induction-birth; 1:2 midwifery care) } \\
\text { (hours) }\end{array}$ & 13.7 & 65207.25 & 11.5 & 56384.96 \\
\hline Mean length of labour (1:1.25 midwifery care) & 7.5 & 89242.50 & 6.9 & 84577.44 \\
\hline Doses of trial medication & 1668 & 583.80 & $\begin{array}{l}342 \times 2 \mathrm{mg} \\
239 \times 1 \mathrm{mg}\end{array}$ & $\begin{array}{c}17660.88 \\
9600.63\end{array}$ \\
\hline Further doses of $2 \mathrm{mg}$ dinoprostone gel ${ }^{*}$ & 70 & 3614.80 & 47 & 2427.08 \\
\hline Vaginal birth & 282 & 1120620.00 & 276 & 1096777.00 \\
\hline Caesarean birth & 83 & 527047.51 & 100 & 634997.00 \\
\hline Total cost & & 1806315.80 & & 1902424.90 \\
\hline Total cost per woman & & 4948.81 & & 5059.64 \\
\hline \multicolumn{5}{|l|}{ Lower threshold } \\
\hline $\begin{array}{l}\text { Median length of labour (induction-birth; 1:2 midwifery care) } \\
\text { (hours) }\end{array}$ & 5.2 & 24749.92 & 2.9 & 35547.04 \\
\hline Mean length of labour (1:1.25 midwifery care) (hours) & 3.4 & 40456.60 & 3.4 & 16670.34 \\
\hline Doses of trial medication & 1668 & 583.80 & $\begin{array}{l}342 \times 2 \mathrm{mg} \\
239 \times 1 \mathrm{mg} \\
\end{array}$ & $\begin{array}{c}17660.88 \\
9600.63 \\
\end{array}$ \\
\hline Further doses of $2 \mathrm{mg}$ dinoprostone gel ${ }^{*}$ & 42 & 2168.88 & 28 & 1445.92 \\
\hline Vaginal birth & 297 & 1180227.50 & 294 & 1168306.00 \\
\hline Caesarean birth & 68 & 431797.96 & 82 & 520697.54 \\
\hline Total cost & & 1679984.60 & & 1736587.60 \\
\hline Total cost per woman & & 4602.70 & & 4618.58 \\
\hline \multicolumn{5}{|l|}{ Upper threshold } \\
\hline $\begin{array}{l}\text { Median length of labour (induction-birth; 1:2 midwifery care) } \\
\text { (hours) }\end{array}$ & 22.2 & 105663.12 & 19.6 & 96099.58 \\
\hline Mean length of labour (1:1.25 midwifery care) (hours) & 11.6 & 138028.40 & 10.9 & 133607.84 \\
\hline Doses of trial medication & 1668 & 583.80 & $\begin{array}{l}342 \times 2 \mathrm{mg} \\
239 \times 1 \mathrm{mg}\end{array}$ & $\begin{array}{c}17660.88 \\
9600.63\end{array}$ \\
\hline Further doses of $2 \mathrm{mg}$ dinoprostone gel ${ }^{*}$ & 109 & 5628.76 & 73 & 3769.72 \\
\hline Vaginal birth & 262 & 1041143.40 & 252 & 1001405.10 \\
\hline Caesarean birth & 103 & 654046.91 & 124 & 787396.28 \\
\hline Total cost & & 1945094.30 & & 2049540.00 \\
\hline Total cost per woman & & 5329.03 & & 5450.90 \\
\hline
\end{tabular}

*Refers to further doses administered after completion of the two doses of vaginal gel provided as trial medication in treatment packs.

without changes in fetal heart rate. Differences in the process of induction did not lead to poorer health outcomes for women or infants. Women preferred an oral induction agent, and use of misoprostol was associated with a modest cost saving to institutions.

\section{Strengths of this study}

Our trial is the second double blind study comparing oral misoprostol with dinoprostone gel, ${ }^{13}$ and the first involving low dose oral misoprostol solution. We blinded participants to treatment, as recommended, ${ }^{14-16}$ which should reduce bias and increase confidence in the validity of our results. Our inclusion criteria represented the spectrum of indications for induction, and with over $70 \%$ of the women we approached agreeing to participate, our results have external validity and are applicable to the general obstetric population requiring induction of labour.

Our trial is the largest to date of oral misoprostol and dino-

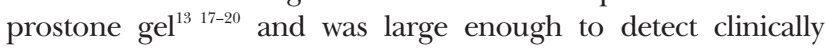
important differences in caesarean birth and vaginal birth not achieved within 24 hours. We were powered to detect a threefold difference in the less common outcome of uterine hyperstimulation with changes in fetal heart rate. For rare maternal and neonatal complications we were powered to detect only large differences. Given the low frequency of such events it would be necessary to recruit tens of thousands of women and their infants. Nevertheless, our results provide reliable evidence on the use of oral misoprostol for induction of labour at term and contribute to the available information about its safety.

\section{Weaknesses of this study}

Our findings of reduced efficacy raise the possibility that our dosing regimen was too low. An incremental increase in dose to $40 \mu \mathrm{g}$ after four hours in the absence of uterine activity, as described by Hofmeyr et $\mathrm{al}^{18}$ and later Dallenbach et $\mathrm{al},{ }^{19}$ may be more appropriate, but difficult to achieve in our trial while maintaining blinding.

\section{Unanswered questions and future research}

The outcome of vaginal birth not achieved in 24 hours $^{9}$ covers women who deliver by caesarean or who give birth vaginally after 24 hours. Vaginal birth achieved after 24 hours reflects a longer time from induction to birth and may reflect an inappropriately low dose of misoprostol. An increase in caesarean birth may reflect uterine hyperstimulation or worrying changes in fetal heart rate. For completeness and to ensure clarity of information, future trials should report both components of this composite outcome.

While the use of misoprostol as an induction agent is associated with cost savings, this is unlikely to propel manufacturers towards seeking appropriate product licensing, ${ }^{21}$ and its use in pregnancy has medicolegal implications for individual practitioners and institutions. Agencies funding health care, however, may be willing to provide indemnity for its use.

While the extent of rare but potentially serious adverse complications such as uterine rupture, maternal or perinatal death, and neonatal acidaemia remain uncertain, regular audit of clinical practice and reporting of such adverse outcomes should be a requirement of clinicians and institutions adopting the use of 


\section{What is already known on this topic}

More than one in four pregnant women have induced labour

Prostaglandins are used to induce labour in more than one in five confinements, and misoprostol, a prostaglandin $\mathrm{E}_{1}$ analogue, is being used increasingly

\section{What this study adds}

There was no significant difference between oral misoprostol and vaginal dinoprostone gel in the risk of not achieving vaginal birth in 24 hours, caesarean section, uterine hyperstimulation with changes in fetal heart rate, or adverse health outcomes for the woman and her infant

Women preferred the oral treatment

misoprostol for the induction of labour. Efforts should be directed to ensure the availability of a licensed low dose $(20 \mu \mathrm{g})$ formulation for use in pregnancy, that is easy to administer orally, while retaining its low cost to enable widespread use, particularly in under-resourced countries.

Contributors: JMD (guarantor) developed the original trial protocol, submitted the protocol to research and ethics committees, obtained funding, developed information sheets and data sheets, coordinated education sessions for midwives and medical staff, prepared treatment packs, recruited women at the Women's and Children's Hospital, collected data, checked all data forms and data entry, analysed and interpreted data, and prepared and revised the manuscript and approved the final version. CAC and JSR developed the original trial protocol, submitted the protocol to research and ethics committees, obtained funding, analysed and interpreted data, and prepared and revised the manuscript and subsequent revisions and approved the final version. Sheree Agett (research midwife) prepared treatment packs, recruited women at the Women's and Children's Hospital and the Lyell McEwin Health Service, and collected data. Kristyn Willson (statistician) gave statistical advice. Neil Hotham (pharmacist) gave advice on the preparation of treatment packs. Gus Dekker coordinated the trial at the Lyell McEwin Health Service. Dirk Ludwig coordinated the trial at the Hervey Bay Hospital.

Funding: During the time this trial was conducted, JMD was the recipient of the Mayne Women's Health Fellowship provided by the research foundation of the Royal Australian and New Zealand College of Obstetricians and Gynaecologists, and a postgraduate medical scholarship provided by the research foundation of the Women's and Children's Hospital. Financial support for a research midwife was obtained through a project grant provided by the Research Foundation of the Women's and Children's Hospital.

Competing interests: None declared.
Ethical approval: Ethical approval was obtained from each institution.

1 Riskin-Mashiah S, Wilkins I. Cervical ripening. Obstet Gynecol Clin North Am 1999;26:243-57.

2 Laws PJ, Sullivan EA. Australia's mothers and babies 2002. Sydney: Australian Institute of Health and Welfare (AIHW), National Perinatal Statistics Unit (NPSU). 2004.

3 Nassar N, Sullivan EA, Lancaster P, Day P. Australia's mothers and babies 1998. Sydney: AIHW National Perinatal Statistics Unit, 2000.

4 Garris RE, Kirkwood CF. Misoprostol: a prostaglandin E1 analogue. Clin Pharm Garris RE, Kir
$1989 ; 8: 627-44$.

5 Collins PW, Pappo R, Dajani EZ. Chemistry and synthetic development of misoprostol. Dig Dis Sci 1985;30:114-7S.

6 Collins PW. Misoprostol: discovery, development and clinical applications. Med Res Rev 1990;10:149-72.

7 Hofmeyr GJ, Gulmezoglu AM. Vaginal misoprostol for cervical ripening and labour induction in late pregnancy. Cochrane Database Syst Rev 2005;(3):CD000941.

8 Alfirevic Z. Oral misoprostol for induction of labour. In: Cochrane Database Syst Rev 2005;(2):CD001338.

9 Hofmeyr GJ, Alfirevic Z, Kelly T, Kavanagh J, Thomas J, Brocklehurst P, et al. Methods for cervical ripening and labour induction in late pregnancy: generic protocol. for cervical ripening and labour induction in
Cochrane Database Syst Rev 2005;(3):CD002074.

10 Curtis P, Evans S, Resnick J. Uterine hyperstimulation. The need for standard terminolCurtis P, Evans S, Resnick J. Uter
ogy. J Reprod Med 1987;32:91-5.

11 Royal Australian and New Zealand College of Obstetricians and Gynaecologists (RANZCOG). Clinical guidelines: intrapartum fetal surveillance. East Melbourne, Victoria: RANZCOG, 2001.

12 Royal College of Obstetricians and Gynaecologists (RCOG). Evidence-based clinical guideline number 8: the use of electronic fetal monitoring. London: RCOG Press, 2001.

13 Tessier F, Danserau. A double blind randomized controlled trial comparing oral misoprostol to vaginal prostaglandin E2 for the induction of labor at or near term. Am J Obstet Gynecol 1997;176:S111.

14 Chalmers I, Hetherington J, Elbourne D, Keirse M, Enkin M. Materials and methods used in synthesizing evidence to evaluate the effects of care during pregnancy and childbirth. In: Chalmers I, Enkin M, Keirse M, eds. Effective care in pregnancy and childbirth. In: Chalmers I, Enkin M, Keirse M, eds.
childbirth. Oxford: Oxford University Press, 1989:39-65.

15 Schulz KF, Chalmers I, Hayes RJ, Altman DG. Empirical evidence of bias: dimensions of methodological quality associated with estimates of treatment effects in controlled trials. JAMA 1995;273:408-12.

16 Kunz R, Oxman AD. The unpredictability paradox: review of empirical comparisons of randomised and non-randomised clinical trials. BMJ 1998;317:1185-90.

17 Gherman RB, Browning J, O'Boyle A, Goodwin TM. Oral misoprostol vs intravaginal prostaglandin E2 for preinduction cervical ripening. A randomized trial. J Reprod Med 2001;46:641-6.

18 Hofmeyr GJ, Alfirevic Z, Matonhodze B, Brocklehurst P, Campbell E, Nikodem VC. Titrated oral misoprostol solution for induction of labour: a multi-centre, randomised Titrated oral misoprostol solution for ind
trial. Br J Obstet Gynaecol 2001;108:952-9. $19 \begin{aligned} & \text { Dallenbach P, Boulvain M, Viardot C, Irion O. Oral misoprostol or vaginal } \\ & \text { dinoprostone for labor induction: a randomized controlled trial. Am J Obstet Gynecol }\end{aligned}$ 2003; $188: 162-7$.

20 Shetty A, Livingstone I, Acharya S, Rice P, Danielian P, Templeton A. A randomised comparison of oral misoprostol and vaginal prostaglandin E2 tablets in labour induction at term. Br J Obstet Gynaecol 2004;111:436-40.

21 Weeks A, Fiala C, Safar P. Misoprostol and the debate over off-label drug use. Br J Obstet Gynaecol 2005;112:269-72.

(Accepted 17 November 2005)

doi $10.1136 /$ bmj. 38729.513819 .63

Department of Obstetrics and Gynaecology, University of Adelaide, Women's and Children's Hospital, North Adelaide, SA 5006, Australia

Jodie M Dodd maternal fetal medicine specialist

Caroline A Crowther professor of obstetrics and gynaecology Jeffrey S Robinson professor of obstetrics and gynaecology

Correspondence to:J Dodd jodie.dodd@adelaide.edu.au 